\title{
Sole Distributors and Incentives to Innovate
}

$\operatorname{AUTHOR}(S)$ :

Flath, David; Nariu, Tatsuhiko

CITATION:

Flath, David ...[et al]. Sole Distributors and Incentives to Innovate. The Kyoto Economic Review 2015, 84(1-2): 74-93

ISSUE DATE:

2015

URL:

https://doi.org/10.11179/ker.84.74

RIGHT: 


\title{
Sole Distributors and Incentives to Innovate
}

\author{
David Flath $^{\text {a* }}$ and Tatsuhiko Nariu ${ }^{\mathrm{b}}$ \\ aProfessor, Faculty of Economics, Ritsumeikan University, Japan \\ ${ }^{b}$ Professor, Graduate School of Management, Kyoto University, Japan
}

\begin{abstract}
An independent firm that is the sole distributor of an upstream monopoly supplier has a stronger incentive to discover and adopt cost-reducing innovations than would a competitive distribution industry bound to the same upstream supplier. This is true whether the downstream pricing behavior is of a Cournot or Bertrand variety, and whether the distributors' rights to innovations are exclusive or may be costlessly imitated. This represents a new efficiency-based explanation for the manufacturer's assignment of exclusive geographic territories to distributors. It can explain why a foreign manufacturer would designate a sole importer to be uniquely responsible for wholesale distribution of its product within the importing country.
\end{abstract}

Keywords: innovation, sole distributor

JEL Classifications: L11, L12

\section{Introduction}

We explore the incentives to innovate in a distribution industry that is organized by an upstream monopoly supplier. Our overarching conclusion is that to preserve the maximum incentives of the downstream distributors to innovate, the upstream (manufacturing) monopolist must organize the downstream industry as a sole distributor-which is, in effect, also a monopoly. This result is robust; it holds whether the downstream pricing behavior is of a Cournot or Bertrand variety, and whether the distributors' rights to innovations are exclusive or may be costlessly imitated.

Our claim is that a sole distributor has a stronger incentive to discover and adopt cost-reducing innovations than would a competitive distribution industry bound to the same upstream supplier. This claim rests on a key point: the contractual stipulations that a manufacturer would impose on its

\footnotetext{
*Corresponding author: Faculty of Economics, Ritsumeikan University, Noji Higashi 1 chome, 1-1 Kusatsu, Shiga 525-8577 Japan. E-mail: flath@fc.ritsumei.ac.jp

This research was supported by a Japan Society for the Promotion of Science Grant-in-Aid for Scientific Research (C), grant no. 15K03749.
} 
designated distributor - be it a monopoly distributor or a competitive industry of distributors - will ensure that the distributor does not erode the marketing channel profit by constricting supply. Therefore, whether it is a sole-distributormonopolist or a competitive industry, its initial supply will be the sameand, as Demsetz (1969) argues, a monopoly's incentive to innovate is actually greater than that of a competitive industry, if the two cases being compared initially supply the same quantity. Our contribution is to broaden the Demsetz analysis to include Cournot industries and not just Bertrand industries, and non-drastic innovations as well as drastic; we look also to apply that analysis to the case of a distribution industry organized by an upstream monopoly producer.

Demsetz's suggestion - namely, that a monopoly's incentive to innovate is actually greater than that of a competitive industry if the two cases being compared initially supply the same quantity - appears at the end of the appendix to his justly famous paper (Demsetz, 1969, pp. 21-22). He uses a numerical example to compare the increased profit from an equal reduction in unit cost for a monopoly and for a firm in a competitive industry, in which the industry outputs are initially the same and in which the demands facing the two industries are also the same. That is, the initial unit cost is higher for the competitive industry than for the monopoly. Because the initial profit of the monopoly is positive but that of the competitive firm is zero, the increased profit from the innovation of the monopoly, but not of the competitive firm, reflects the Arrow effect, also called the "replacement effect." Nevertheless, in the Demsetz example, the increased profit from innovation is larger for the monopoly than for the competitive firm. This holds true, even when the reduction in unit cost is sufficient to confer a monopoly on the previously competitive firm - a "drastic" innovation, in the parlance of Arrow (1962). ${ }^{1}$ In context, the point of Demsetz's example is to caution against wrongly supposing that, merely because of the replacement effect, a monopoly must necessarily have a weaker incentive to seek a cost-reducing innovation than would a competitive industry. However, the example seems contrived: why, for example, would a monopoly and a competitive industry each have the same initial output? The Schumpeterian notion that monopolies might be more innovative than competitive industries persists in the literature, but not because of the Demsetz argument.

Our focus is on the organization of downstream distributors by an upstream monopoly supplier. The question we pose is not whether a monopoly generally gains more from innovation than would a competitive firm - a matter of Schumpeter versus Arrow. Rather, the question we pose is this: does the sole

\footnotetext{
${ }^{1}$ In the Demsetz example, the industry demand curve is $\mathrm{p}=100-\mathrm{q}$, and the initial unit cost is $\mathrm{c}=95$ for the competitive industry and $\mathrm{c}=90$ for the monopoly. The innovation reduces the unit cost of each by the same amount, to $c^{\prime}=15$ for the competitive firm and $c^{\prime}=10$ for the monopoly. The gain in profit from the innovation is 2,000 for the monopoly but $1,806.25$ for the competitive firm.
} 
distributor of an upstream monopolist gain more from an innovation than would have a firm in a Bertrand or Cournot industry of distributors under contract to the same upstream monopolist? Our answer is that a sole distributor would gain more, and the Demsetz example illustrates our argument. The upstream monopoly, whether it designates a sole distributor or enters contracts with competing distributors, would set the wholesale price and a flat fee to maximize profit. If the upstream monopolist designates a sole distributor, it would set the wholesale price to be equal to its own unit cost, and set a flat fee to fully appropriate the downstream profit. If it contracts with a Bertrandcompetitive industry of distributors, it would set the wholesale price to be equal to the monopoly price minus its own unit cost. If it contracts with a Cournot-competitive industry of distributors, it would set the wholesale price such that the downstream Cournot equilibrium attains the same final price as that under the other arrangements just described, and appropriate any downstream profit through a flat fee. The perceived unit cost of a sole distributor, a Bertrand competitor, and a Cournot competitor would thus all differ, but the initial final price would be the same for each. An innovation by a downstream firm in any of these three scenarios that lowered the firm's own unit cost, holding the wholesale price constant, would match the Demsetz example in an important respect. It would amount to the same additive reduction in perceived unit cost, but from different initial levels, depending on whether the firm is a sole distributor, a Bertrand competitor, or a Cournot competitor, with the same initial final price for each. The Demsetz example thus illustrates one special instance that compares the gain from a specific drastic innovation by a sole distributor with that of a Bertrand competitor, in which the gain by the sole distributor is larger. We explore more general settings, with arbitrary demand (not necessarily linear), non-drastic innovation as well as drastic, and Cournot-competitive firms as well as Bertrand. In all of the settings we consider, as in the Demsetz example, the sole distributor gains more from an innovation than would a Bertrand or Cournot-competitive firm, all else being equal.

Our finding amounts to a new efficiency-based explanation for a manufacturer's assignment of exclusive geographic territories to distributors. A relevant example is the common practice of a foreign manufacturer who designates a sole importer to be uniquely responsible for the wholesale distribution of its product within the importing country. An important advantage of such arrangements is the superior incentive to seek cost-reducing innovation, which such a soledistributor designation confers.

\section{Benchmark case: vertically integrated monopoly}

We begin our analysis with a benchmark case, which is of a vertically integrated monopoly facing the same demand and the same costs as in the various 
other examples we will consider. Let there be a monopoly producer with zero manufacturing cost, ${ }^{2}$ and let there be a constant unit cost of distribution/ marketing. Denote the monopoly price as $p^{*}(c)$ and the monopoly profit as $\Pi^{*}(c)$, where $c$ is the unit cost. If manufacturing and distribution are vertically integrated, then the added profit to the monopoly in each period from an innovation that lowers its unit cost from $\bar{c}$ to $\underline{c}$ equals: ${ }^{3}$

$$
\begin{aligned}
v^{*} & =\int_{\frac{c}{c}}^{\bar{c}}\left(-d \pi^{*} / d c\right) d c \\
& =\int_{\underline{c}}^{\bar{c}} D\left(p^{*}(c)\right) d c .
\end{aligned}
$$

This is our benchmark case for comparing the incentive to innovate under alternative arrangements. Because it takes as given the market power of the manufacturer, it is in some sense an imperfect situation-although for the purpose of our analysis, it is the best among the realistic alternatives in encouraging innovation. We set to one side the point of Choi, Lee, and Stefanadis (2003) that the manufacturer might, by mistake, integrate with the wrong downstream firm-namely, one that is less adept at invention than another. If you like, we accept that such mistakes are an unavoidable fact of life. More specifically, in comparing the incentive to innovate across regimes, we will assume that the organization of inventive activity is the same for all of them. That is, we will assume that regimes differ only in the reward for invention, and not in the technology of invention.

${ }^{2}$ The assumption that manufacturing costs are zero is made to simplify the algebraic notation. As long as the manufacturing cost is proportionate to output, the constant of proportionality - even if it is zero-has no bearing on our results.

${ }^{3} \mathrm{~A}$ little bit of calculus is helpful:

$$
\begin{aligned}
\frac{d \pi^{*}}{d c} & =\frac{d\left(\left(p^{*}-c\right) D\left(p^{*}\right)\right)}{d c} \\
& =\frac{\partial \pi}{\partial p} \frac{d p^{*}}{d c}+\frac{\partial \pi}{\partial c} \\
& =\frac{\partial \pi}{\partial c} \\
& =-D\left(p^{*}(c)\right) .
\end{aligned}
$$

Note that $\frac{\partial \pi}{\partial p}=0$, by the envelope theorem. Here, we follow the excellent exposition of Tirole (1988, pp. 390-393). 
What we characterize as the "incentive to innovate" is the maximum willingness to pay an outside discoverer for use of an invention, per time period. Equally, it is what the user of the invention would gain if he or she discovered it and is not licensing its use to others. We will explore the incentive to innovate for various regimes in which the monopoly manufacturer eschews vertical integration with the downstream distribution industry and instead enters a contractual arrangement with it. The timeline for all such cases we consider is as follows. [1] A monopoly manufacturer designates one firm as sole distributor, or not. [2] A manufacturer sets wholesale price $w$ and a flat fee. [3] Authorized distributors (sole distributor if so designated, or all distributors if no sole distributor is designated) pay the flat fee, and seek cost-reducing innovation that is either exclusive (attainable by at most one distributor) or non-exclusive (available to all distributors, if introduced by any). [4] Ex-post any innovation, the authorized distributors buy for resale from the manufacturer, pay the wholesale price per unit previously set by the manufacturer, and attain a market equilibrium, either Bertrand or Cournot.

\section{Downstream industry is a sole distributor}

Consider the case in which the monopoly assigns a single independent firm to be its exclusive outlet (i.e., a sole distributor). We presume that the competition to become such a sole distributor is such that all economic rents accrue to the manufacturer. We assume also that the monopoly producer commits to a particular wholesale price before innovation by the downstream distributors.

In the case of the sole distributor, the manufacturer sets the wholesale price equal to its marginal cost (zero), $w_{S}=0$, and appropriates the profit by a flat fee, thus attaining a first-best outcome. For an independent monopoly that purchases at the wholesale price equal to manufacturer marginal cost, the benefit from innovation is transparently identical to that of a vertically integrated monopoly.

\section{Downstream distributors are Bertrand competitors}

Now consider the case where the monopoly manufacturer deals with a Bertrand industry of identical distributors. The manufacturer sets a wholesale price equal to the simple monopoly price minus the unit cost of distribution, $w_{B}=p^{*}(\bar{c})-\bar{c}$, and attains a first-best outcome conditional on the distributors' unit cost being $\bar{c}$. However, the incentive to innovate differs from that of a sole distributor. The Bertrand distributors have a smaller incentive to innovate. First, consider the possibility of innovation that can be costlessly imitated, and so is non-exclusive. There is no gain to a Bertrand competitor from such an innovation. The sole distributor has a superior incentive to undertake innovations that could be costlessly imitated by rivals. 
Next, consider the case where the innovator enjoys the exclusive right to its invention. Suppose that one distributor introduces an innovation that lowers its unit cost from $\bar{c}$ to $\underline{c}$. Here, there are two subcases - namely, drastic and non-drastic innovation - which we will address in order. First, if the monopoly price of the innovating firm is larger than the unit cost of the other firms (nondrastic innovation):

$$
p^{*}\left(w_{B}+\underline{c}\right) \geq \mathrm{w}_{B}+\bar{c},
$$

then the innovating firm would price just below the unit cost of the others, $p=\mathrm{w}_{B}+\bar{c}-$ epsilon. In the case of non-drastic innovation, the profit conferred on the Bertrand innovator in each period would be:

$$
v_{B}=(\bar{c}-\underline{c}) D\left(p^{*}\left(w_{B}+\bar{c}\right)\right)<v^{*} .
$$

In Figure $1, v_{B}$, the profit of a Bertrand firm that introduces a non-drastic innovation, is represented by the area of the shaded rectangle, which is clearly smaller than that of the shape enclosed by the broken line, which represents $v^{*}$, the profit of a sole distributor that introduces the same innovation.

Figure 1. Non-drastic innovation. A Bertrand distributor that lowers its unit costs from $\bar{C}$ to $\underline{C}$ gains an amount $v_{B}$ equal to the shaded rectangle, which is smaller than the gain of a monopoly distributor $v *$ indicated by the area of the polygon bordered by the broken line.

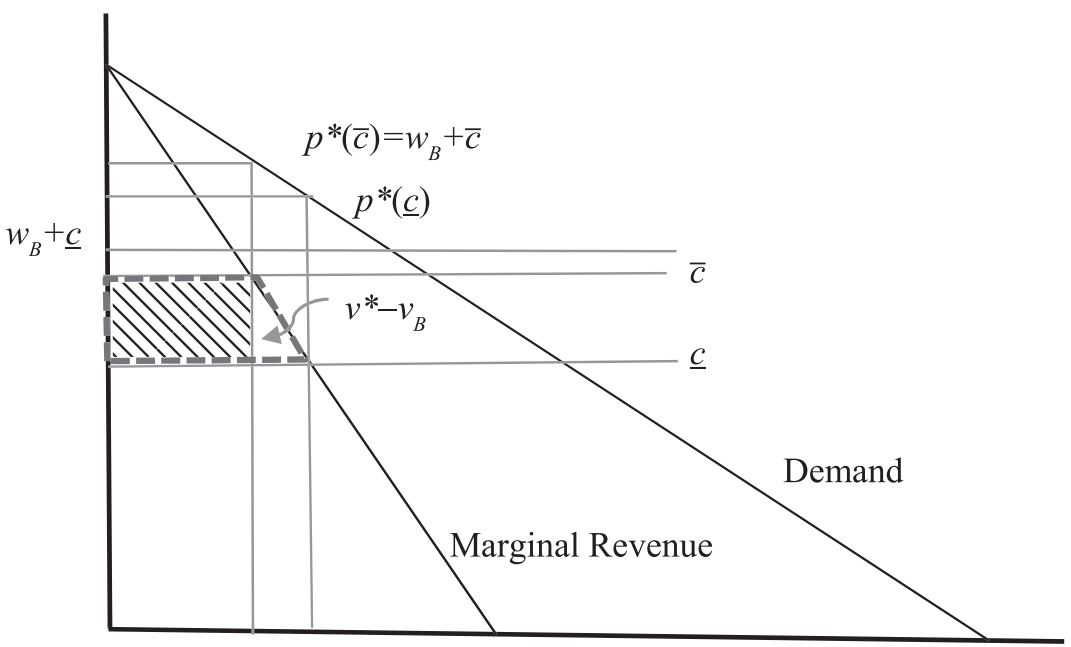


Second, if the monopoly price of the innovating Bertrand distributor is actually lower than the unit costs of the other firms (drastic innovation):

$$
p^{*}\left(w_{B}+\underline{c}\right)<\mathrm{w}_{B}+\bar{c},
$$

it would set the simple monopoly price given its unit cost, $p=p^{*}\left(\mathrm{w}_{B}+\underline{c}\right)$.

In the case of drastic innovation by a Bertrand competitor, the innovator's profit in each period equals its own monopoly profit given the wholesale price $w_{B}$ :

$$
\begin{aligned}
v_{B} & =\int_{w_{B}+\underline{c}}^{\infty} D\left(p^{*}(c)\right) d c \\
& =v^{*}-\int_{\underline{c}}^{w_{B}+\underline{c}} D\left(p^{*}(c)\right) d c+\int_{\bar{c}}^{\infty} D\left(p^{*}(c)\right) d c .
\end{aligned}
$$

However, the manufacturer sets the wholesale price $w_{B}$ to appropriate maximum profit for itself, prior to innovation; therefore, the last term in the above expression is: ${ }^{4}$

$$
\int_{\bar{c}}^{\infty} D\left(p^{*}(c)\right) d c=w_{B} D\left(p^{*}(\bar{c})\right)
$$

Thus, it follows that

$$
\begin{aligned}
v_{B} & =v^{*}-\int_{\underline{c}}^{w_{B}+\underline{c}} D\left(p^{*}(c)\right) d c+w_{B} D\left(p^{*}(\bar{c})\right) \\
& =v^{*}-\int_{\underline{c}}^{w_{B}+\underline{c}}\left(D\left(p^{*}(c)\right)-D\left(p^{*}(\bar{c})\right)\right) d c<v^{*}
\end{aligned}
$$

\footnotetext{
${ }^{4}$ Arguably, the manufacturer would be mindful of the effect of wholesale price $w_{B}$ on incentives to innovate. A higher $w_{B}$ causes some innovations to be drastic that would otherwise have been nondrastic, but reduces the gain from innovations that would have been drastic anyway or non-drastic anyway. We ignore these subtleties.
} 
We conclude that for drastic innovation, as for non-drastic, the benefit of innovation to the Bertrand-competitive firm is smaller than the benefit would be to a vertically integrated monopolist or sole distributor: $v_{B}<v^{*}$.

Fundamental to this result, the perceived marginal cost of the Bertrand distributor, $w_{B}+\underline{c}$, lies above the true marginal cost, $\underline{c}$, but that of the sole distributor does not. ${ }^{5}$ Though not obvious, for an innovation that would be drastic for a Bertrand competitor, the effect on post-innovation profit of the lower marginal cost of a sole distributor compared to a Bertrand innovator would be greater than the pre-innovation profit of the sole distributor. The pre-innovation profit is replaced by the post-innovation profit, and so it is a marginal cost of innovation - positive for a sole distributor, but zero for a Bertrand competitor, and thus our result. The Bertrand distributor has a smaller benefit from a drastic innovation than would a sole distributor from the same innovation.

Figure 2 presents the same analysis, just related, in diagram form. In Figure 2, $v_{B}$, the profit of a Bertrand firm that introduces a drastic innovation, is represented by the area of the triangle enclosed by the broken line above $w_{B}+\underline{c}$. Additionally, $v^{*}$, the profit of a sole distributor that introduces the same innovation, is represented by the area of the polygon enclosed by the broken line between $\bar{c}$ and $\underline{c}$. The area of each of the two shaded regions, a triangle and a rectangle, equal the pre-innovation gross profit, appropriated by a franchise fee in the case of a monopoly distributor and through the mark-up of wholesale price over manufacturer marginal cost in the case of a competitive distributor. It is evident in Figure 2 that $v_{B}<v^{*}$.

Our analysis of exclusive innovation has presumed that only one distributor can innovate. Alternatively, innovations could be exclusive to each inventor, but have many inventors - in which case, the private gain to innovation of each of the Bertrand distributors would be zero. Even with multiple inventors, our conclusion would hold; it would even be strengthened. Organizing the independent distributor as a monopoly rather than a Bertrand-competitive industry enlarges its incentive to seek cost-reducing innovation.

${ }^{5}$ The marginal cost facing the Bertrand innovator is

$$
\begin{aligned}
w_{B}+\underline{c} & =p^{*}(\bar{c})-\bar{c}+\underline{c} \\
& =\frac{\bar{c}}{1-\frac{1}{\xi}}-\bar{c}+\underline{c} \\
& =\frac{\bar{c}}{\xi-1}+\underline{c} .
\end{aligned}
$$


Figure 2. Drastic innovation. A Bertrand-competitive distributor that lowers its unit costs from $\bar{C}$ to $\underline{C}$, gains $v_{B}$ represented by the area of the triangle enclosed by the broken line above $w_{B}+\underline{c}$. A monopoly distributor gains the larger amount $v^{*}$, represented by the area of the polygon enclosed by the broken line between $\bar{c}$ and $\underline{c}$. The area of each of the two shaded regions, a triangle and a rectangle, are equal to each other; each is also equal to the pre-innovation gross profit, which is appropriated by franchise fee in the case of a monopoly distributor and through mark-up of wholesale price over manufacturer marginal cost in the case of a competitive distributor. The monopoly distributor thus gains more from the drastic innovation than would a Bertrand distributor by the amount $v *-v_{B}>0$, also shown in the figure.

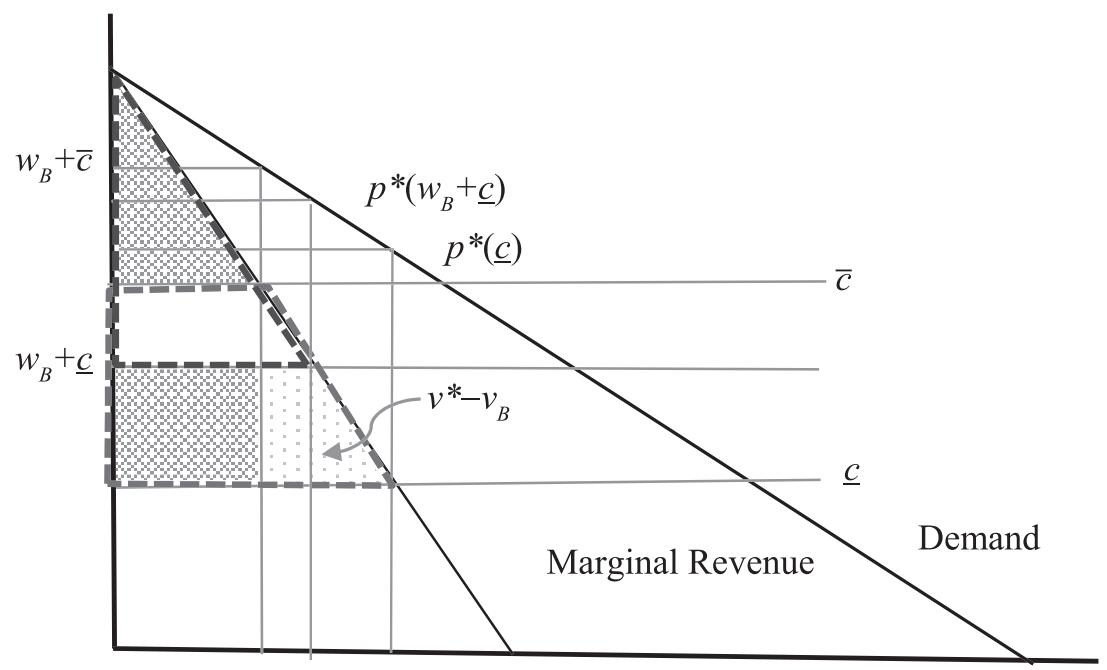

\section{Downstream distributors are Cournot competitors}

If the downstream distributors are identical Cournot competitors rather than Bertrand, the same logic applies, with some variations. The manufacturer initially sets a wholesale price that induces the $n$ Cournot distributors to supply the quantity that attains maximum vertical profit given the initial unit cost, $\bar{c}$, and the monopoly manufacturer appropriates the profit with a flat fee. That wholesale price is easily found to be

$$
w_{C}=p^{*}(\bar{c})\left(1-\frac{1}{n \xi}\right)-\bar{c},
$$


where $\xi$ is the elasticity of demand. If the number of distributors is large, then the wholesale price set by the manufacturer approaches the simple monopoly price minus the unit cost of distribution, as in the Bertrand case:

$$
\lim _{n \rightarrow \infty} w_{C}=p^{*}(\bar{c})-\bar{c},
$$

and the manufacturer sets a zero flat fee, just as in the Bertrand case. For finite numbers of Cournot distributors $n$, the flat fee is positive.

For non-exclusive innovations, Cournot distributors (unlike Bertrand) do obtain some benefit, but it is smaller than what a sole distributor would obtain. This is because in the Cournot equilibrium, unlike the Bertrand equilibrium, there is a positive profit margin, though it approaches zero as the number of distributors grows large:

$$
\frac{p-w_{c}-\underline{c}}{p}=\frac{1}{n \xi}
$$

For innovations that are exclusive (attainable for at most one firm), the individual incentive is greater than if non-exclusive, but still smaller than for a sole distributor, whether the innovation is drastic or non-drastic. Let us consider drastic innovation first. The same logic we used to analyze the profit from drastic innovation in Bertrand also applies to Cournot, except the wholesale price set by the manufacturer may differ between the two cases. In the case of drastic innovation by a Cournot competitor, the innovator's profit in each period equals its own monopoly profit given the wholesale price $w_{c}$ :

$$
\begin{aligned}
v_{C} & =\int_{w_{C}+\underline{c}}^{\infty} D\left(p^{*}(c)\right) d c \\
& =v^{*}-\int_{\underline{c}}^{w_{C}+\underline{c}} D\left(p^{*}(c)\right) d c+\int_{\bar{c}}^{\infty} D\left(p^{*}(c)\right) d c .
\end{aligned}
$$

However, the manufacturer sets the wholesale price $w_{c}$ and the total-industry flat fee $F$ to appropriate the maximum profit for itself prior to innovation; therefore, the last term in the above expression is

$$
\int_{\bar{c}}^{\infty} D\left(p^{*}(c)\right) d c=w_{C} D\left(p^{*}(\bar{c})\right)+F .
$$


Thus, it follows that

$$
\begin{aligned}
v_{C} & =v^{*}-\int_{c_{C}}^{w_{C}+\underline{c}} D\left(p^{*}(c)\right) d c+w_{C} D\left(p^{*}(\bar{c})\right)+F \\
& =v^{*}-\int_{\underline{c}}^{w_{C} \underline{ \pm}}\left(D\left(p^{*}(c)\right)-D\left(p^{*}(\bar{c})\right)-\frac{F}{w_{C}}\right) d c \\
& <v^{*} .
\end{aligned}
$$

We conclude that for drastic innovation, the benefit of innovation to the Cournot firm is smaller than the benefit would be to a vertically integrated monopolist or sole distributor: $v_{C}<v^{*}$. Direct comparison of Cournot and Bertrand is a bit messy, because some innovations that would be drastic if the distributors are Cournot would be non-drastic if the distributors were Bertrand. ${ }^{6}$ An innovation that would be drastic for either Bertrand or Cournot confers a larger gain for Bertrand than for Cournot.

The source of the larger gain from innovation of a sole distributor versus a Cournot distributor is that the marginal cost facing the Cournot innovator, $w_{C}+\underline{c}$, is larger than the true marginal cost of producing, $\underline{c}$, but for a sole

${ }^{6}$ For Bertrand, an innovation is drastic (i.e., would lead to monopoly) if

$$
p^{*}\left(w_{B}+\underline{c}\right)<\mathrm{w}_{B}+\bar{c}
$$

while for Cournot, an innovation is drastic if

$$
p^{*}\left(w_{C}+\underline{c}\right)<\mathrm{w}_{C}+\bar{c}
$$

Some tedious algebraics establish that for Bertrand, an innovation is drastic if

$$
\frac{\bar{c}-\underline{c}}{\bar{c}}>\frac{1}{1-\frac{1}{\xi}},
$$

while for Cournot, an innovation is drastic if

$$
\frac{\bar{c}-\underline{c}}{\bar{c}}>\frac{\frac{1}{\xi}\left(1-\frac{1}{n \xi}\right)}{1-\frac{1}{\xi}} .
$$


distributor the perceived marginal cost is the true marginal cost. ${ }^{7}$ Additionally, the effect on incentive to seek a drastic innovation of the lower marginal cost of the sole distributor more than offsets the larger replacement effect for a sole distributor, compared to a Cournot distributor.

The Cournot distributors will have each paid any flat fee before innovation, and so it is a sunk cost ex-post innovation (i.e., at the production stage). In the case of drastic innovation by just one distributor, all the other $n-1$ distributors will have paid the flat fee, but in the end supply zero. Each pays the flat fee, holding a positive likelihood of itself being the drastic innovator; in the case of drastic innovation by just one, this turns out to be a losing bet for all but one of them.

Turning attention now to non-drastic (exclusive) innovations by atomistic Cournot distributors, the individual gain is smaller than for a sole distributor; the analysis matches that of Bertrand, compared to a sole distributor. If the monopoly manufacturer has set the wholesale price beforehand and is committed to maintaining it (as we assume for Bertrand), then the non-drastic innovation confers a smaller gain than could be enjoyed by a sole distributor. The non-drastic Cournot innovator does not capture the entire market as would a Bertrand innovator: we need to remember here that the innovation is exclusive. In the limit, if the number of Cournot distributors is large $(n \rightarrow \infty)$, the industry supply and price remain unchanged ex-post innovation, $p=p^{*}(\bar{c})$, and the market share of the non-drastic Cournot innovator (firm 1 , say) approaches: ${ }^{8}$

$$
s_{1}=\xi\left(\frac{\bar{c}-\underline{c}}{p^{*}(\bar{c})}\right)<1
$$

${ }^{7}$ The marginal cost facing the Cournot innovator is

$$
\begin{aligned}
w_{C}+\underline{c} & =p^{*}(\bar{c})\left(1-\frac{1}{n \xi}\right)-\bar{c}+\underline{c} \\
& =\bar{c}\left(1-\frac{1}{\xi}\right)^{-1}\left(1-\frac{1}{n \xi}\right)-\bar{c}+\underline{c} \\
& =\left(\frac{1-\frac{1}{n}}{\left(1-\frac{1}{\xi}\right)\left(\xi-\frac{1}{n}\right)}\right) \bar{c}+\underline{c} .
\end{aligned}
$$

${ }^{8}$ In the atomistic case here $(n \rightarrow \infty)$, if $\xi\left(\frac{\bar{c}-\underline{c}}{p^{*}(\bar{c})}\right) \geq 1$, then the innovation is drastic, meaning that $S_{1}=1$. 
In this instance (i.e., exclusive, non-drastic innovation in an atomistic industry), the private gain to the Cournot innovator, $v_{C}$, is smaller than that of a Bertrand innovator, $v_{B}$, or sole distributor, $v^{*}$. Specifically,

$$
v_{C}=s_{1} v_{B}<v_{B}<v^{*} .
$$

With a finite number of Cournot distributors, things become more complicated. With a finite number of Cournot distributors, a non-drastic innovation by one of them would expand industry supply, but by less than if the innovator were a sole distributor. Additionally, the non-innovators would retrench but continue to supply output at the same high unit cost as before. So, the innovator would itself earn a smaller profit than would a sole distributor, but the non-innovators would enjoy some profit. The incentive to innovate (net private gain to the innovator) is the difference between the profit of the innovator and that of a non-innovator. Because the profit of a Cournot innovator is smaller than that of a sole distributor, its incentive to innovate (i.e., the innovator's profit minus a non-innovator's profit) is also smaller than that of a sole distributor. We conclude that the net incentive to seek a non-exclusive, non-drastic innovation is smaller for a Cournot distributor than for a sole distributor. This matches our result for a Bertrand distributor.

As in the case of Bertrand distributors, if innovation is exclusive but not limited to one firm, the private gain of each Cournot distributor is smaller than if it were the only innovator (whether the innovation is drastic or non-drastic). Our conclusion that sole distributorship maximizes the incentive to innovate is strengthened if exclusive innovations can be multiple, for Cournot as for Bertrand.

\section{Models with renegotiation after the initial period $^{9}$}

Our examples thus far suppose that the manufacturer who enters a contract with independent distributors sets the terms initially, once and for all-exemplifying, in effect, a one-period model with only a single instance of innovation. For instance, in the models considered thus far, if the monopoly

\footnotetext{
${ }^{9}$ Mathewson and Winter (1994) developed a model of franchising with exclusive territories and the renegotiation of flat fees following product innovation by the franchisee. They argue that the exclusive territory (an exclusive right to establish new outlets within a designated region) encourages innovation precisely because innovation then precipitates renegotiation of the franchise fee. In our framework, process innovation triggers renegotiation only if a sole distributorship - an exclusive territory—had not already been established.
} 
manufacturer allows a competitive Bertrand distribution industry, it sets its wholesale price equal to the profit-maximizing retail price minus the preinnovation marginal distribution cost, $w_{B}=p^{*}(\bar{c})-\bar{c}$, and keeps it there, even after innovation occurs. If it designates a sole distributor of its products, then it sets its wholesale price equal to manufacturing marginal cost $\left(w_{S}=0\right)$ and keeps it there, and charges a franchise fee equal to the pre-innovation profit, $\left(p^{*}-\bar{c}\right) D\left(p^{*}(\bar{c})\right)$, making no adjustments after innovation. A slightly more elaborate model is possible that takes into account the likelihood that the initial wholesale price and flat fee would be renegotiated ex-post innovation, in a way that leaves both the upstream monopoly and the innovative distributor both better off than had the wholesale price and flat fee been unchanged. We next characterize these models with the renegotiation of contract following the initial period.

First, consider the Bertrand case with exclusivity of innovation. Suppose that if one Bertrand distributor has discovered an innovation, the wholesale price and franchise fee would be renegotiated in accordance with the Nash bargaining solution. At the end of the initial period, the manufacturer would designate the innovator as a sole distributor, set a wholesale price equal to manufacturing marginal cost $\left(w_{S}=0\right)$, and set a new mutually agreed franchise fee that divides the rent that is created by moving to a sole distributorship. That rent arises from the resolution of a successive profit margin distortion and because of the superior incentive of a sole distributor to further innovate compared to the incentive of a Bertrand distributor. To attain a first-best outcome, the manufacturer would have to organize the downstream industry as a sole distributor from the initial period. If the independent distributors are Bertrand competitors - if even for a single period - their incentive to seek innovation is still attenuated, compared to that of a sole distributor.

Next, consider the Cournot case with exclusivity of innovation and possible renegotiation after the first period. The manufacturer's initial wholesale price and franchise fee are subject to renegotiation ex-post innovation. As with Bertrand, once an innovation has occurred, the first-best case is for the producer to enter a sole-distributor agreement with the innovator and renegotiate the wholesale price. As with Bertrand, the prospect of this would enlarge the private gain from innovation of the Cournot distributor. However, the first-best outcome for the manufacturer would still require that it organize the downstream industry as a sole distributor from the very beginning.

From all the cases examined thus far, it is clear that for the monopoly manufacturer to encourage innovation by downstream distributors, the first-best outcome requires assigning a sole distributor and appropriating the economic rent through an initial flat fee. Nonetheless, we still have not exhausted all the possibilities, nor even the possibilities considered thus far in the literature. This is because we have yet to examine cases where the monopoly manufacturer could not impose a flat fee. Previous investigators have begun from that position (no flat fee), which we will next take up. 


\section{Cases where a flat fee cannot be imposed}

If a flat fee cannot be imposed, then a monopoly manufacturer that sells through a sole distributor is a case of successive monopolies. As is well known, the double margin of successive monopolies compounds the deadweight loss and erodes the combined profit. To be more specific, in the case of a linear final demand and constant unit cost, the monopoly manufacturer's profit when distributing through an independent monopoly distributor is half as great as under vertical integration. Nevertheless, the recent literature on innovation under vertical structures assumes that successive monopoly distortion is an immutable constraint. This is a bold assumption —one that we do not embrace, but that others do.

In a study that is relevant to our discussion, Banerjee and Lin (2003) explore cases where a monopoly manufacturer sells through independent distributors that are Cournot competitors. Zikos and Kesavayuth (2010) extend the model to cases with technological spillovers (that is, in which imitation is possible, though possibly is costly). In the Banerjee and Lin (and Zikos and Kesavayuth) scenario, the manufacturer cannot impose a flat fee. If, furthermore, it does not pre-commit to a wholesale price, the Cournot distributors calculate that an innovation by any of them would induce a wholesale price increase by the manufacturer. This would actually make the private gain from innovation larger rather than smaller, if retrenchment by the Cournot rivals is the dominant effect on the innovator's profit induced by the wholesale price increase. This is the main result of Banerjee and Lin (2003). However, their argument presumes that the manufacturer does not impose a flat fee, for the increase in the wholesale price following a downstream innovation is strictly the result of the successive monopoly distortion that a flat fee would negate, as in the examples we have explored in this study. For a further analysis of this issue, refer to the study of Nariu, Wang, Flath, and Lei (2014), which argues that the manufacturer will impose a flat fee if it can do so.

In yet another study related to this discussion, Matsushima and Mizuno (2012) extend the Banerjee and Lin (2003) framework to cases with sole distributorship. They find that sole distributorship leads to less innovation by downstream firms - not more, as we have claimed. ${ }^{10}$ Let us take a moment to understand the basis for this contrary result. The Matsushima-Mizuno model posits an upstream duopoly that distributes through a downstream industry

\footnotetext{
${ }^{10}$ Matsushima and Mizuno (2012) cast their analysis in terms of the logical complement of exclusive dealing, which they dub "procurement ability." In their model, the downstream industry is a duopoly. If neither downstream firm has "procurement ability," then each deals exclusively with one upstream firm. They characterize the situation in which each downstream firm is a sole distributor (each deals exclusively with a different upstream firm) as a case with "less upstream competition" compared to the situation in which neither is a sole distributor.
} 
of Cournot competitors. They suppose that the upstream firms cannot impose flat fees, and do not pre-commit to particular wholesale prices (the wholesale prices are set after innovation by the downstream firms). Vertical integration by both upstream firms would configure the industry as a Cournot duopoly. With an independent downstream industry, given the assumption of no flat fees, a successive price-cost-margin distortion arises. This distortion is greater under sole distributorship — in which each distributor deals exclusively with a different upstream firm, as opposed to each dealing with both upstream firmsand the output sold by the downstream firms is correspondingly smaller; this is the fundamental reason why a sole distributorship reduces rather than enhances incentives for downstream innovation in this model. Again, the assumption of no flat fee is a crucial difference from our proposed framework for analyzing sole agency.

\section{Relevance of the argument to actual instances of sole distributorship}

The results of our analysis suggest that the encouragement of innovation could motivate the manufacturer of a branded consumer product to organize the downstream industry as a sole distributor, in what would be a geographic monopoly. We offer three examples of sole distributorships where we think our argument applies - namely, sole importer contracts, business-format franchisees with area development agreements, and product franchisees with exclusive territories.

\subsection{Sole importer contract}

The first example of sole distributorship is a foreign manufacturer that designates a particular firm as the "sole importer" uniquely authorized to wholesaledistribute the product within the importing country. This is especially common in Japan, as detailed by Flath and Nariu (2008). Sometimes the sole importer is a wholly owned subsidiary of the foreign manufacturer, which in our analysis is equally consonant with the encouragement of downstream innovation - the sole distributor and vertically integrated monopolist have the same incentive. ${ }^{11}$ The

\footnotetext{
${ }^{11}$ Wholesale affiliates of foreign firms comprise a significant portion of the stock of foreign direct investment in Japan. Touyou Keizai, Gaishi keikigyou souran (Survey of Foreign-affiliated Companies in Japan), annual (since 1986) lists basic data on virtually all the large, foreign-owned enterprises operating in Japan. This listing includes all respondents with a book value of equity exceeding JPY50 million and with greater than 49\% foreign ownership. About one-third of these 1,372 large foreign subsidiaries operating in Japan in 1997 were primarily engaged in wholesaling - 468 firms in all. The wholesale affiliates of foreign firms comprise a significant portion of the stock of foreign
} 
maintenance of a sole-importer arrangement requires the active obstruction of parallel imports (that is, the import of goods of the same brand through channels other than through the designated sole importer). The obstruction of parallel imports is often difficult, and under the anti-monopoly law of Japan and some other countries may be illegal.

On the relevance of our argument to sole importer contracts, consider that the sole importer is tasked with the organization and direction of a nationwide wholesale and retail distribution network. In Japan, this typically has entailed establishing and enforcing resale price maintenance contracts, as in cases involving ladies' handbags, chinaware, ice cream, water purification filters, and athletic shoes (Flath and Nariu, 2008). The management of such a directed marketing channel is rife with opportunities for innovation. The superior incentives of a sole distributor in seeking such innovation, compared to those of competing distributors, accounts for the foreign manufacturers' choice of sole importer contracts in these cases.

\subsection{Business-format franchisee with an area development agreement}

Another example of sole distributorship where our argument applies is a business-format franchisee with an exclusive geographic territory. Businessformat franchises allow use of the franchisor brand name and business plan at a stipulated location, upon payment of an initial franchise fee and ongoing payment of royalties (typically $5 \%$ or $6 \%$ of retail sales revenue). Familiar examples include fast-food restaurants such as McDonald's and Burger King, fitness clubs such as Gold's Gym, and motels such as Econo Lodge. As many as $60 \%$ of business-format franchisors enter "area development agreements" with at least some franchisees (222 of 397 large US franchisors, observed in 1992: Brickley, 1999, p. 761). These ensure the exclusive right to operate multiple outlets within a broad geographic area, such as a city, county, state, or region.

A franchisee with an area development agreement is a sole distributor within the designated area. In the absence of any area development agreement or its effective equivalent, ${ }^{12}$ competing multi-unit franchisees would be vying for the same demanders. Our argument applies. An innovation by any one competing franchisee would allow it to expand its number of outlets (possibly by buying out

direct investment in Japan. Encouragement of innovation could be a contributing motivation. This pattern is not limited to Japan. Hanson, Mataloni, and Slaughter (2001) note that 20\% of the total worldwide sales of foreign affiliates of US multinationals were the sales of their foreign wholesale affiliates (p. 25).

${ }^{12}$ Kalnins and Lafontaine (2004) found that in the fast-food franchise industry in Texas, franchisees typically operate multiple units that serve geographically contiguous markets, even without area development agreements. In other words, the coverage of area development agreements actually understates the true extent of de facto sole distributorships. 
pre-existing rival outlets), but its gain from such expansion, given the wholesale prices set by the franchisor, would be smaller than that of a sole distributor who introduced the same innovation. A franchisee with an area development agreement - a sole distributor - has a greater incentive to innovate than would competing franchisees serving the same market.

Previous analysts of area development agreements, including Brickley (1999) and Kalnins and Lafontaine (2004), have focused on possible benefits, such as the resolution of free-riding problems among franchisees and economies of governance and monitoring that come about when outlets of the same multiunit franchisee are geographically concentrated. The promotion of innovation is an additional or alternative rationale for area development franchise contracts.

\subsection{Product-franchisee who is a sole distributor}

A final example where our argument applies is a product franchise with assigned customers. Product franchisors supply branded products through a network of affiliated dealers that possibly includes both wholesale and retail distributors, and do not conform to a prescribed business format. Examples include automobile dealers, automotive parts distributors, bicycles, home electronics, and soft-drink bottlers. Product franchise agreements typically entail the payment of an initial franchise fee and the ongoing purchase of the product itself from the franchisor, but no royalty payments based on receipts. Where customer assignments or exclusive geographic territories are stipulated, product franchise agreements are sole distributorships.

The scope for innovation by product franchisees extends beyond the management of a directed marketing channel or logistic network to include production itself. A soft-drink bottler or yogurt-drink bottler that is assigned an exclusive geographic territory by the drink company stands to profit more from cost-reducing innovation than if it were not assigned such a territory. The exclusive territories may exist for that reason, and not to discourage opportunistic quality depreciation. After all, there are effective and relatively low-cost ways of observing whether soft drinks are being watered down. In the parlance of economics, soft drink quality is contractible. Innovation is, by its nature, not contractible. Assigning an exclusive territory may be the best way for a franchisor to promote innovation by independent product franchisees, but is not likely to be the best way to protect product quality.

In the United States, since the Sylvania decision, ${ }^{13}$ non-price vertical restraints such as the assignment of exclusive geographic territories have been subject to the rule of reason. The courts have become particularly tolerant of such stipulations, but that could change, given the vicissitudes of anti-trust

${ }^{13}$ Continental Television v. GTE Sylvania, 433 U.S. 36 (1977). 
litigation. Our demonstration that sole distributorships confer superior incentives to seek innovation strengthens the argument that such arrangements should continue to be allowed.

\section{Conclusion}

At least since Arrow (1962), if not before, economists have debated the effects of industrial organization on the allocation of resources to invention. Though seldom remarked upon, this is a question that concerns not just government policy, but the marketing policies of profit-seeking firms. A manufacturing firm that designates an independent firm as its sole distributor within a geographic territory needs to consider the effects of its doing so on the incentive to seek cost-reducing marketing innovations. We have argued that that incentive is improved by organizing the downstream distributors as local monopolies rather than as atomistic competitors, so long as the manufacturer sets its wholesale pricing and franchise fee to maximize its own profit. This explains the practice of actual firms that sell through sole distributors, and exposes a social benefit of the same.

In considering the effect of sole distributorship on incentives to innovate, one must take into account that a manufacturer that designates a sole distributor will take steps to prevent that sole distributor from eroding channel profit by restricting supply. In evaluating the effect of sole distributorship on incentives to innovate, the correct comparison is therefore not between a monopoly and a competitive industry facing the same demand with the same costs, but between a monopoly and a competitive industry facing the same demand and also initially choosing the same quantity (because of the constraint set by the manufacturer). It so happens that Demsetz (1969, pp. 21-22) undertook exactly the same comparative analysis (for the linear demand case, with drastic innovation by a Bertrand firm or by a monopoly) as we do here, but without the motivation or context of a sole-distributor contract.

\section{References}

Arrow, K.J. (1962) "Economic Welfare and the Allocation of Resources for Invention," in R.R. Nelson (ed.) The Rate and Direction of Inventive Activity. Princeton University Press for the National Bureau of Economic Research, Princeton, NJ, pp. 609-625.

Banerjee, S. and Lin, P. (2003) "Downstream R\&D, Raising Rivals' Costs, and Input Price Contracts," International Journal of Industrial Organization 21: 79-96.

Brickley, J.A. (1999) "Incentive Conflicts and Contractual Restraints: Evidence from Franchising," Journal of Law and Economics 42.2: 745-774.

Choi, J.P., Lee, G., and Stefanadis, C. (2003) "The Effects of Integration on R\&D Incentives in Systems Markets," Netnomics 5: 21-32. 
Continental Television v. GTE Sylvania, 433 U.S. 36 (1977).

Demsetz, H. (1969) "Information and Efficiency: Another Viewpoint," Journal of Law and Economics 12.1: 1-22.

Flath, D. and Nariu, T. (2008) "Parallel Imports and the Japan Fair Trade Commission," The Japanese Economy 35.1: 3-28.

Hanson, G.H., Mataloni, R.J., and Slaughter, M.J. (2001) "Expansion Strategies of U.S. Multinational Firms," in S.M. Collins and D. Rodrik (eds.) Brookings Trade Forum Brookings Trade Forum 2001. Brookings Institution Press, Washington, DC, pp. 245-294.

Kalnins, A. and Lafontaine, F. (2004) "Multi-unit Ownership in Franchising: Evidence from the Fast-Food Industry in Texas," Rand Journal of Economics 35.4: 747-761.

Mathewson, F. and Winter, R. (1994) "Territorial Restrictions in Franchise Contracts," Economic Inquiry 32: 181-192.

Matsushima, N. and Mizuno, T. (2012) "Profit-Enhancing Competitive Pressure in Vertically Related Industries," Journal of the Japanese and International Economies 26: $142-152$.

Nariu, T., Wang, H., Flath, D., and Lei, J. (2014) "Ryuutsuu gyousha ni yoru hiyou sakugen toushi: kibou kouka, keiyaku no taimingu to furanchaizu ryou (Distributors' cost-reducing investment: scale effects, contract timing and franchise fees)," Keizai rongyou (Kyoto University) 188.2: 31-46.

Tirole, J. (1988) The Theory of Industrial Organization. MIT Press. Cambridge, MA.

Touyou Keizai, Gaishi keikigyou souran (Survey of Foreign-affiliated Companies in Japan), annual (since 1986). Touyou Keizai. Tokyo.

Zikos, V. and Kesavayuth, D. (2010) "Downstream R\&D, Raising Rival's Costs, and Input-price Contracts: A Comment on the Role of Spillovers," Economics Bulletin 30.4: 3018-3025. 